\title{
Off-pump coronary bypass: Is it for everyone?
}

Lawrence I. Bonchek, MD

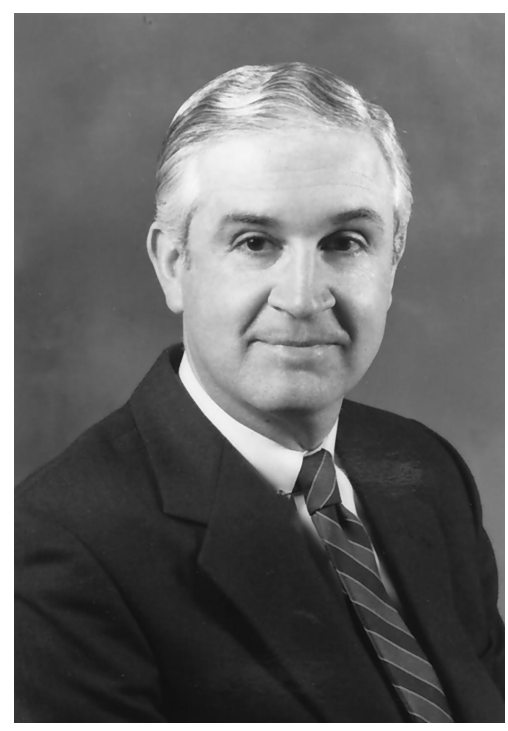

See related article on page 598 .
As the island of knowledge expands, so too do the shores of ignorance.

-Author unknown

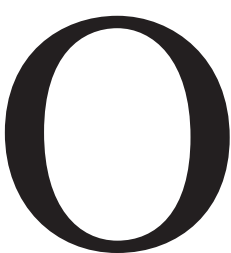

ff-pump coronary artery bypass (OFFCAB) has been adopted enthusiastically by many surgeons throughout the world, but despite more than 5 years' experience and progressive refinement of techniques and equipment, many surgeons use it only sporadically and some use it hardly at all. This reluctance persists despite the insistence by many of OFFCAB's advocates that it can be performed regularly by any competent surgeon without compromising the safety and sustained improvement that are hallmarks of the standard operation.

It has never been clear whether the reluctance of many surgeons to adopt OFFCAB is due to their unwillingness to struggle with a tedious technique even though it has "obvious" benefits, or whether, as others have insisted, there is still insufficient evidence to show that its modest benefits are worth all the trouble. ${ }^{1,2}$ The comprehensive and thoughtful article in this issue of the Journal by Mack and associates $^{3}$ expands our understanding of these issues, but it also highlights our ignorance.

Mack and associates ${ }^{3}$ conducted a retrospective review of a 5-year experience with 12,540 patients who underwent isolated coronary artery bypass grafting (CABG), of whom 1915 underwent OFFCAB. In the introduction to their report, they ask four questions that frame the core of our uncertainties about OFFCAB:

1. Can off-pump surgery be safely incorporated into a surgical practice and be performed by most surgeons?

2. Is there a significant learning curve to the adoption of beating-heart surgery?

3. Does incorporation of off-pump surgery into a surgical practice lead to better overall outcomes?

4. Are the improved outcomes reported with beating-heart surgery related to the technique or to individual surgeon experience and expertise?

I would make two additions to this list. As a corollary to question 4, I would also ask: What is the evidence for better outcomes with beating-heart surgery? I would also add a question 5: Are the risk models in the Society of Thoracic Surgeons (STS) National Database, which are derived from experience with on-pump CABG, valid for assessing risk for patients undergoing OFFCAB?

To answer question 1, Mack and associates ${ }^{3}$ commendably analyzed the work of 36 surgeons individually, which unfortunately is rarely done in surgical reports. The number 36 is artifactually inflated by staffing turnover, as there are currently 22 surgeons in the practice. It turns out that the same 6 surgeons who were early, enthusiastic adopters of OFFCAB ("high adopters") carried out 73\% of all OFFCAB procedures, whereas the remaining surgeons did OFFCAB sporadically, and 8 surgeons still do fewer than 10 OFFCAB cases per year ("low adopters"). In the 5 -year period before the introduction of OFFCAB, the composite mortality rate for $\mathrm{CABG}$ of the 3 lowest adopters was $38 \%$ greater than the composite mortality rate of the 3 highest adopters $(4.0 \%$ vs $2.9 \%, P<.001)$. Clearly, OFFCAB was being performed predominantly by the most accomplished surgeons. If, as common sense suggests, this group's experience is typical, the answer to question 1 is that although OFFCAB can be safely incorporated into a large practice, it appears unlikely, at least for now, that OFFCAB will be done regularly by most surgeons. This is true 
even in a trailblazing program in which low adopters can study the technique in house, without having to attend extramural teaching programs. Indeed, the percentage of cases done off pump by the low adopters in the last 2 years of the study actually declined, from $16 \%$ in 1999 to $9.6 \%$ in 2000. If so, are surgeons likely to adopt OFFCAB in a group where no one is enthusiastic about it? I base this question on the observation that among the 4 operating surgeons in our own group, the current use of OFFCAB ranges from $3 \%$ to $50 \%$.

Question 2 has broad implications, because it is the patients operated on too early, not the surgeons, who really experience the "learning curve." When OFFCAB was first introduced, many centers carried out postoperative angiography routinely, and there was an undesirable incidence of reoperation. In the study of Mack and associates, ${ }^{3}$ however, it does appear that there was no significant learning curve, because there was no observable trend toward lower mortality and morbidity as the study progressed. This observation is both remarkable and commendable. Selection of patients for OFFCAB was at the discretion of the individual surgeon, and an observable learning curve was probably avoided by starting with straightforward single-graft cases and only progressing to multivessel cases after techniques were refined. This combination of good clinical judgment and technical expertise, which seems to have characterized the high adopters, offers a valuable lesson about how to adopt a new and difficult technique, but this approach has not been equally successful everywhere.

The answer to question 3 is not available from this study. Although the Mack and associates ${ }^{3}$ assert that "gradual adoption and integration of beating-heart surgery, as reflected in the last 2 years of the study, led to a trend toward overall improved CABG outcomes," this conclusion is suspect for various reasons. First, during the years of this study, as throughout the history of cardiac surgery, there were many refinements in surgical technique, anesthetic management, drug therapy, hemostasis, arterial grafting techniques, and so on. In an uncontrolled, retrospective study, any improvement, even if statistically significant (which this is not), would be the result of a combination of several factors in addition to, or even aside from, the introduction of OFFCAB. Second, if "high-risk" patients (more about risk later) were preferentially treated off pump, most would have been operated on by high adopters, who had the lowest mortality rates even before the introduction of OFFCAB. Progressive diversion of high-risk patients to those surgeons could explain a slight trend toward overall improved CABG outcomes.

Particularly relevant to this concern is a previous presentation of combined experience by the Dallas and the Washington Hospital Center groups at the 2001 meeting of the STS. ${ }^{4}$ They reported early mortality rates similar to those of the study of Mack and associates ${ }^{3}$ (1.8\% off pump vs 3.5\% on pump) and concluded that there were "consistent findings of increased early mortality associated with cardiopulmonary bypass." 4 In answer to questions during the discussion period about the possibility that surgeons performing the off-pump cases "represent a skilled group that might achieve technically superior results in all patients," the authors acknowledged that the possibility was "intriguing" but also "difficult to assess and politically charged." It is therefore all the more commendable that, despite such difficulties, they have now analyzed this possibility. We can see that it was necessary to do so, because even the small demonstrable benefit of OFFCAB may not be due entirely_or even principally_to the technique itself.

Question 4 directly addresses this central issue of the influence of the individual surgeon on the success of the technique. Mack and associates ${ }^{3}$ acknowledge that "the outcome improvement observed with off-pump surgery was not due solely to the technique and that the individual surgeon may have played a significant role." The effect of this phenomenon may be even greater than it seems, as is apparent if one compares the results of on-pump CABG (ONCAB) in this study with the benchmark results in the STS database. I will use 1998 and 1999 data from the STS database, because those years fall in the middle of this 5 -year study and have already been analyzed and reported with separate data for OFFCAB and ONCAB. ${ }^{5}$

The overall risk-adjusted mortality rate for ONCAB in the report of Mack and associates ${ }^{3}$ was $3.9 \%$, which is significantly greater than the risk-adjusted mortality rate of $2.9 \%$ in the STS database. In contrast, the risk-adjusted mortality for OFFCAB in this report was $1.9 \%$, which is lower than the $2.3 \%$ in the STS database. In part these disparities may be due to the inaccuracy of using the same risk-adjustment model for two disparate techniques such as OFFCAB and ONCAB, as discussed later. More important, these disparities reinforce the observation that the surgeons capable of better results than the national averages were primarily doing OFFCAB procedures. These high adopters may also have been more comfortable with arterial grafting, which would explain the increased use of arterial grafts in OFFCAB cases and may have contributed to the mortality disparities, because arterial grafting is associated with reduced operative mortality. Unequal case allocation could also explain why the rate of reoperation for bleeding in patients undergoing ONCAB (3.4\%) was higher than the STS database rate $(2.9 \%)$, and why prolonged ventilation was necessary in $10.5 \%$ of ONCAB cases, compared with $6.5 \%$ in the STS database.

This concern about differences in surgical expertise is applicable to any comparison of OFFCAB and ONCAB that does not have the same surgeons doing all the operations. It even applies to the previously mentioned report from the 
STS database, ${ }^{5}$ which found lower mortality and morbidity with OFFCAB. Because the STS database does not adjust for the experience and expertise of the surgeons who use one technique or another, nor for the subjective criteria surgeons use in selecting cases for OFFCAB, unexplained biases may subtly influence its comparison of the two techniques.

This brings us to question 5, and the complex issue alluded to earlier of assessing the results of OFFCAB with previously derived models for risk adjustment. No riskadjustment model can identify all confounding variables, and there are always some unidentified confounders in any model; it can only be hoped that they are unimportant. However, the STS model was developed in a cohort of patients that had ONCAB in 1994 and 1995, and it is reasonable to suggest that it missed confounding variables that are unique to OFFCAB and could affect mortality, morbidity, and the selection of patients for OFFCAB. These include the presence of intramyocardial coronary arteries; diffuse coronary disease with small, poor-quality target vessels; aortic atherosclerosis that precludes a side-biting clamp for proximal anastomoses; left ventricular hypertrophy, which makes it hard to position the heart; and other factors. The role of the surgeon's experience and expertise must also be analyzed. Most of the necessary data are not being collected, and some probably cannot be, because they are highly subjective and impossible to compare among different institutions. Even if we had the data, it would take years to weight them properly. Any new risk-adjustment model for OFFCAB that included relevant variables would require a new analysis to validate the model.

Clearly, because the importance of so many variables is not and cannot be known, the conclusions of nonrandomized, experiential reports will always be suspect. For example, the STS database report concluded that OFFCAB significantly reduced postoperative length of stay from 6.97 to 6.14 days, the incidence of prolonged mechanical ventilation from $6.51 \%$ to $4.13 \%$, and the risk-adjusted operative mortality from $2.9 \%$ to $2.3 \%$. Yet in our own group, the ONCAB, risk-adjusted numbers for those years are as follows: length of stay 6.1 days, prolonged mechanical ventilation $3.7 \%$, and risk-adjusted mortality $1.1 \%$. Should we realistically anticipate statistically significant improvement if we aggressively adopt OFFCAB, or should we continue to refine our reported techniques 6,7 and use OFFCAB only in selected circumstances?

Randomized studies are therefore essential, because they eliminate the problems of risk adjustment and can be designed so that all operations are done by the same surgeons. Of course, it must be emphasized that randomized studies are not a panacea; they still rely on subjective surgical judgments, which may not be generalizable to all institutions. The first such study, carried out at three hospitals in the Netherlands by pioneers in OFFCAB, has recently been reported. ${ }^{8}$ A total of 281 patients were randomly allocated after they had been judged suitable for either technique, and all surgeons were "experienced in both off pump and on pump bypass surgery." Although all patients had sternotomy, the patients and cardiologists were not blinded to treatment group. At 30 days' follow-up, there were no differences in mortality, intensive care unit stay, stroke, atrial fibrillation, myocardial infarction, use of blood products, quality of life, and hospital cost-parameters that might have been expected to benefit from OFFCAB. The only significant improvements with OFFCAB were less release of creatine kinase isoenzyme $\mathrm{MB}$ and shorter postoperative stay ( 6 days for OFFCAB vs 7 days for ONCAB). Because OFFCAB was done with clamping of single coronary arteries, whereas ONCAB was done with crystalloid cardioplegia and global ischemia, the difference in enzyme release is understandable. It is also unimportant, because ONCAB can also be done with single-vessel occlusion, or with intermittent global ischemia without cardioplegia.6,7 OFFCAB patients did average 1 day less hospitalization, but readiness for discharge is a highly subjective decision that could have been biased by the lack of blinding. Another randomized study was carried out by a single surgeon (John Puskas at Emory University), in which patients and nonoperative caregivers were blinded. ${ }^{9}$ Once again, there was significantly less release of myocardial enzyme in the OFF$\mathrm{CAB}$ group, the OFFCAB group length of stay was 1 day shorter, and the OFFCAB group received fewer transfusions. But results were otherwise the same in the two groups.

These remarks should not be misinterpreted as an argument that OFFCAB is not a useful technique. On the contrary, it is certainly advantageous in such circumstances as for older patients with renal or pulmonary disease, and undoubtedly in many others. It is important to remember, however, that thus far it has only been shown to be better than ONCAB for noncritical end points in selected patients in the hands of selected surgeons. That there are differences in surgical skill among surgeons is something that we all know (else why would we travel so far to watch live surgical demonstrations by recognized technical masters?) but never discuss publicly. After all, if we did not have confidence in ourselves, we could not go to work in the morning. Until now, disparities in skill have been most salient in regard to uncommon or extraordinarily challenging operations, such as thoracoabdominal aneurysms and Ross procedures, and most surgeons have had the selfawareness and common sense to avoid or to refer elective operations they were not comfortable performing. But will that self-restraint remain in force when it is needed for the adult cardiac surgeon's bread-and-butter procedureCABG? These admittedly unsettling considerations are 
mentioned because a technically demanding operation is being offered in place of a remarkably successful, exhaustively studied, and consistently reproducible procedure performed by a vast cadre of trained, experienced surgeons. If the use of OFFCAB is to be extended to more patients and to all surgeons, it is essential to demonstrate, with properly designed risk models and/or randomized studies, that OFF$\mathrm{CAB}$ offers benefits to those patients at the hands of all surgeons. We are waiting eagerly for the evidence.

\section{References}

1. Bonchek LI, Ullyot DJ. Minimally invasive coronary bypass: a dissenting opinion. Circulation. 1998;98:495-7.

2. Bonchek LI. Editorial: some thoughts on minimally invasive coronary bypass. Asian Cardiovasc Thorac Ann. 1999;7:82-3.

3. Mack M, Bachand D, Acuff T, Edgerton J, Prince S, Dewey T, et al. Improved outcomes in coronary artery bypass grafting with beatingheart techniques. J Thorac Cardiovasc Surg. 2002;124:598-607.
4. Magee MJ, Jablonski KA, Stamou SC, Pfister, AJ, Dewey TM, Dullum MK, et al. Elimination of cardiopulmonary bypass improves early survival for multivessel coronary artery bypass patients. Ann Thorac Surg. 2002;73:1196-203.

5. Cleveland JC, Shroyer LW, Chen AY, Peterson E, Grover FL. Offpump coronary artery bypass grafting decreases risk-adjusted mortality and morbidity. Ann Thorac Surg. 2001;72:1282-9.

6. Bonchek LI, Burlingame MW, Vazales BE, Lundy EF, Gassmann CJ. Applicability of noncardioplegic coronary bypass to high-risk patients. J Thorac Cardiovasc Surg. 1992;103:230-7.

7. Bonchek LI. Technical considerations for coronary artery bypass without cardioplegia. J Card Surg. 1992;7:333-41.

8. Van Dijk D, Nierich AP, Jansen EW, Nathoe HM, Suyker WJ, Diephuis JC, et al. Early outcomes after off-pump versus on-pump coronary bypass surgery: results from a randomized study. Circulation. 2001;104:1761-6.

9. Puskas JD, Williams WH, Duke PG, Staples J, Marshall JJ, McCall SA, et al. Off-pump coronary artery bypass grafting provides complete revascularization while reducing myocardial injury, transfusion requirements, and length of stay: a prospective randomized comparison of 200 unselected patients having OPCAB versus CABG. $J$ Thorac Cardiovasc Surg. In press.

Access to The Journal of Thoracic and Cardiovascular Surgery Online is reserved for print subscribers!

Full-text access to The Journal of Thoracic and Cardiovascular Surgery Online is available for all print subscribers. To activate your individual online subscription, please visit The Journal of Thoracic and Cardiovascular Surgery Online, point your browser to http://www.mosby.com/itcvs, follow the prompts to activate your online access, and follow the instructions. To activate your account, you will need your subscriber account number, which you can find on your mailing label (note: the number of digits in your subscriber account number varies from 6 to 10). See the example below in which the subscriber account number has been circled:

\section{Sample mailing label}

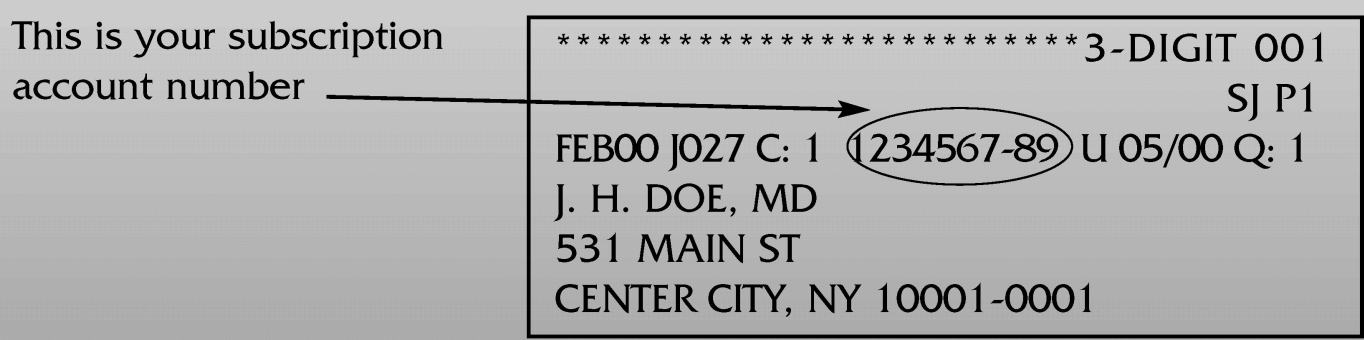

Personal subscriptions to The Journal of Thoracic and Cardiovascular Surgery Online are for individual use only and may not be transferred. Use of The Journal of Thoracic and Cardiovascular Surgery Online is subject to agreement to the terms and conditions as indicated online. 